\title{
Monotherapy versus Polytherapy in Epilepsy: a Framework for Patient Management
}

\author{
J.H. Schneiderman
}

\begin{abstract}
The long-standing debate between proponents of monotherapy and those of polytherapy for treatment of epilepsy has been rekindled by the recent development of several new antiepileptic drugs. The likelihood of improved seizure control on polytherapy must be weighed against the risk of increased side effects, complex drug interactions and cost. Providing maximal seizure control while avoiding overtreatment is a challenge which requires an ongoing critical evaluation of each patient's management. This review provides a framework for decision-making by considering issues affecting the choice between monotherapy and polytherapy in five clinical situations: 1) newly diagnosed epilepsy; 2) seizures on monotherapy; 3) seizures controlled on polytherapy; 4) not controlled on polytherapy; 5) change in medical condition.
\end{abstract}

\begin{abstract}
RÉSUMÉ: La monothérapie versus la polythérapie dans l'épilepsie: un cadre pour le traitement des patients. Le vieux débat entre les promoteurs de la monothérapie et ceux de la polythérapie dans le traitement de l'épilepsie a été repris à cause du développement récent de plusieurs nouveaux médicaments antiépileptiques. La probabilité d'un meilleur contrôle des crises par une polythérapie doit être évaluée par rapport au risque d'effets secondaires plus importants, d'interactions médicamenteuses complexes et du coût de la médication. C'est un défi que d'arriver à un contrôle maximal des crises tout en évitant de surtraiter, ce qui demande une évaluation critique constante du traitement de chaque patient. Cette revue fournit un cadre pour la prise de décision en considérant les raisons qui influencent le choix entre la monothérapie et la polythérapie dans cinq situations cliniques: 1) un nouveau diagnostic d'épilepsie; 2) des crises sous monothérapie; 3) un contrôle des crises sous polythérapie; 4) une absence de contrôle sous polythérapie; 5) un changement dans l'état médical du patient.
\end{abstract}

Can. J. Neurol. Sci. 1998; 25: S9-S13

The introduction of five new drugs for the treatment of epilepsy in Canada within the last decade has provided physicians and their patients with new treatment options. However, in some ways this has complicated the management of epilepsy and rekindled the debate concerning the use of monotherapy vs. polytherapy. This review will outline five clinical situations in which the choice between single and multiple drug treatment should be carefully considered. Some of the important issues in each situation will be reviewed in order to provide a framework for clinical decision making.

\section{Newly Diagnosed Epilepsy}

Most authorities now agree that monotherapy is the appropriate choice in newly diagnosed epilepsy. Between $70-75 \%$ of patients achieve a one year remission (one year seizure-free) ) $^{1-3}$ with a single appropriate antiepileptic drug. Seizures are completely controlled in about forty to fifty percent of newly diagnosed patients. ${ }^{2-6}$ Compliance is better and the risk of side effects is reduced with monotherapy. ${ }^{7,8}$ Several well controlled trials have now demonstrated that there is no significant difference in efficacy for generalized tonic-clonic seizures among the standard antiepileptic drugs (phenobarbital, primidone, carbamazepine, phenytoin and sodium valproate). ${ }^{2-4,6}$ In some studies carbamazepine was superior to other drugs in treating partial seizures $^{6}$ but this was not confirmed in other studies. ${ }^{2,3}$
Recent studies indicate that the newer antiepileptic drugs, lamotrigine ${ }^{9,10}$ (357 patients), vigabatrin ${ }^{11,12}$ (87 patients), gabapentin $^{13,14}$ (150 patients) and topiramate ${ }^{15}$ (48 patients) are also effective as monotherapy in controlling new onset generalized tonic-clonic seizures and partial seizures with or without secondary generalization in adults and clobazam is effective in children $^{16}$ (220 patients). Preliminary evidence suggests that lamotrigine monotherapy is also effective in children with absence seizures. ${ }^{17}$ Although only a small number of comparative trials have been carried out, the efficacy of lamotrigine or vigabatrin monotherapy is comparable to carbamazepine.9,11,12

Drug selection is based primarily on seizure type or epilepsy syndrome (Table 1) as well as the adverse event profile. For example, phenobarbital and primidone were not as well tolerated as the other standard drugs especially in children. ${ }^{2-4,6}$ Side effects were less frequent and severe with lamotrigine or vigabatrin than with carbamazepine..$^{9,11,12}$ Individual patient characteristics may also influence the choice of a drug (Table 2).

Patients with more than one seizure type should be treated, if

From the Division of Neurology and Department of Physiology, University of Toronto and Wellesley Hospital, Toronto.

Reprint requests to: J.H. Schneiderman, Room 1116 E.K. Jones Building, Welleslcy Hospital, 160 Wellesley Street, E., Toronto, Ontario, Canada M4Y $1 J 3$ 
Table 1: Choice of antiepileptic drug by seizure type and epilepsy syndrome.

\begin{tabular}{|c|c|c|}
\hline Seizure type & $\begin{array}{l}\text { Initial } \\
\text { Monotherapy }\end{array}$ & $\begin{array}{l}\text { Alternative } \\
\text { monotherapy } \\
\text { or Add-on }\end{array}$ \\
\hline $\begin{array}{l}\text { Partial onset } \\
\text { (simple or complex) } \\
\text { with or without } \\
\text { secondary generalized } \\
\text { tonic-clonic seizures }\end{array}$ & $\begin{array}{l}\text { Carbamazepine } \\
\text { Phenytoin } \\
\text { Valproic acid }\end{array}$ & $\begin{array}{l}\text { Clobazam } \\
\text { Gabapentin* } \\
\text { Lamotrigine } \\
\text { Phenobarbital } \\
\text { Primidone } \\
\text { Topiramate* } \\
\text { Vigabatrin* }\end{array}$ \\
\hline
\end{tabular}

Generalized seizures

\begin{tabular}{|c|c|c|}
\hline Tonic-clonic & $\begin{array}{l}\text { Carbamazepine } \\
\text { Phenytoin } \\
\text { Valproic acid }\end{array}$ & $\begin{array}{l}\text { Clobazam } \\
\text { Gabapentin* } \\
\text { Lamotrigine } \\
\text { Phenobarbital } \\
\text { Primidone } \\
\text { Topiramate* } \\
\text { Vigabatrin* }\end{array}$ \\
\hline Absence & $\begin{array}{l}\text { Valproic acid } \\
\text { Ethosuximide }\end{array}$ & $\begin{array}{l}\text { Clobazam } \\
\text { Lamotrigine } \\
\text { Topiramate* }\end{array}$ \\
\hline $\begin{array}{l}\text { Myoclonic } \\
\text { Atonic/akinetic } \\
\text { Tonic }\end{array}$ & Valproic acid & $\begin{array}{l}\text { Clobazam } \\
\text { Lamotrigine } \\
\text { Topiramate* }\end{array}$ \\
\hline
\end{tabular}

\begin{tabular}{|c|c|c|}
\hline \multicolumn{3}{|l|}{ Epilepsy Syndrome } \\
\hline $\begin{array}{l}\text { Juvenile Myoclonic } \\
\text { Epilepsy }\end{array}$ & Valproic acid & $\begin{array}{l}\text { Carbamazepine } \\
\text { Lamotrigine } \\
\text { Phenytoin }\end{array}$ \\
\hline $\begin{array}{l}\text { Benign Rolandic } \\
\text { Epilepsy** }\end{array}$ & Carbamazepine & $\begin{array}{l}\text { Clobazam } \\
\text { Phenytoin } \\
\text { Valproic acid }\end{array}$ \\
\hline Infantile spasms & Vigabatrin & $\begin{array}{l}\text { ACTH } \\
\text { Corticosteroids }\end{array}$ \\
\hline
\end{tabular}

* not yet approved for monotherapy in Canada

** treatment is usually not necessary

possible, with a single broad spectrum agent such as valproate or lamotrigine rather than 2 or more individual drugs specific for each seizure type. Compliance is improved with a single agent while the risks of adverse events and pharmacokinetic interactions are diminished. It may be appropriate to consider discontinuing treatment after one year in children or two years in adults whose seizures are completely controlled. This can be accomplished successfully in approximately $60 \%$ of appropriately selected patients. ${ }^{18,19}$

If the seizures are completely controlled with monotherapy, but the patient suffers side effects despite lowering the medication dosage, the patient should be switched to alternative monotherapy. One strategy is to add the second drug and withdraw the first one as soon as the patient has been stabilized. Abrupt discontinuation of the first drug before adequate levels of the second drug have been reached could result in seizure recurrence. Furthermore, if the patients suffer a hypersensitivity reaction to the second drug requiring discontinuation, they may be left without any treatment for their seizures. Patients may be prepared to accept a brief period of side effects on polytherapy rather than run the risk of recurrent seizures. Titrating one drug up while simultaneously withdrawing another drug may confuse patients and lead to medication errors. A written schedule can be very helpful.

\section{Seizures on Monotherapy}

The diagnosis should be critically re-evaluated if the seizures are not improved with monotherapy. It is important to ensure that the diagnosis of epilepsy is correct, that the seizure type has been correctly identified and that a thorough search for underlying causes has been carried out. The history and EEG should be reviewed to determine whether the appropriate drug has been chosen for the patient's seizure type (Table 1) and that an adequate dose of the drug has been prescribed. Although drug levels may provide a helpful guide to dosing with some of the standard anti-epileptic drugs (phenytoin, carbamazepine, phenobarbital, valproic acid), they should not be the only consideration. Some patients may not achieve adequate seizure control until their levels are higher than the "therapeutic" range. It may be preferable to increase dosage up to the maximum tolerated dose, rather than adhering too strictly to the drug levels.

One of the most common reasons for failure of anti-epileptic drug therapy is poor patient compliance. ${ }^{20,21}$ This is best assessed with a careful history, however, drug levels may also be helpful under these circumstances. Patient education regarding the diagnosis and treatment as well as lifestyle factors, such as sleep deprivation, alcohol and drug abuse, which may interfere with seizure control, may lead to alterations in behaviour which improve seizure control without changing medication.

It is unlikely that a drug which has been ineffective on its own will be effective in combination with other medications. Therefore, patients who do not improve with appropriate monotherapy should be switched to an alternative agent. The situation is more complicated when the first agent significantly reduces the seizures but does not completely control them. A second drug may be added or the patient may be switched to an alternative drug. Unfortunately, there are no controlled clinical trials comparing alternative monotherapy with add-on polytherapy. However, alternative monotherapy may be effective in reducing seizures or even eliminating them in some patients $\mathrm{s}^{22,23}$ while avoiding drug interactions, minimizing side effects and decreasing costs. Establishing an effective dose of the alternate drug may sometimes require considerable time. Discontinuing the first drug while titrating the new agent may result in an increase in seizures. Patients may prematurely conclude that the second drug is ineffective and discontinue it before an adequate trial has been completed.

An alternative approach is to add the second agent. Drug combinations which do not result in significant pharmacokinetic interactions are preferred under these circumstances. Adding a second agent may improve seizure control in $25-50 \%$ of patients, but is likely to result in complete control in only $5-10 \%$ of patients. ${ }^{4,7,11}$ However, if the seizures are completely controlled with combination therapy, consideration should be given to withdrawing the first agent in order to minimize side effects. ${ }^{7}$ For example, over $40 \%$ of patients whose seizures were completely 
Table 2: Some patient characteristics to consider in choosing drugs.

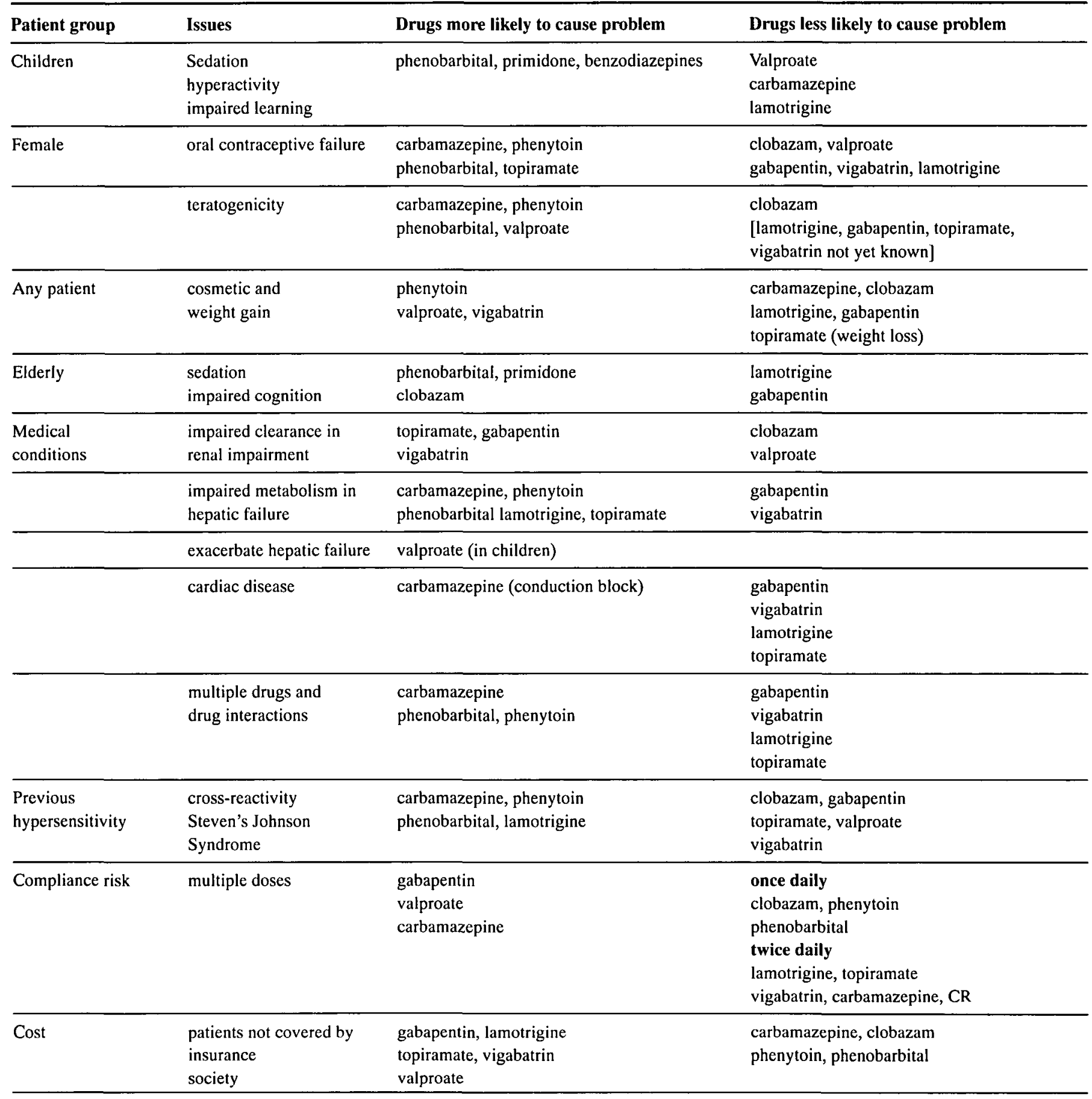

controlled when lamotrigine was added to valproate, phenytoin or carbamazepine, remained seizure-free on lamotrigine monotherapy. ${ }^{7}$ The first drug can be re-instituted if the seizures recur. However, sufficiently long observation periods are required to ensure that seizure recurrences do not simply represent the natural fluctuation in seizure frequency.

There may be a tendency to add 3 rd or 4th agents when addon therapy results in an apparent improvement, but not complete seizure control. However, there are no controlled trials to support this practice. It is probably preferable to proceed to alterna- tive add-on agents rather than continuing to add to the polypharmacy which increases the risk of side effects with little if any improvement in seizure control. Under these circumstances, the first add-on drug can be stopped abruptly and an alternative addon agent tried. It is again imperative that the patient be carefully re-evaluated to ensure correct diagnosis and treatment. Surgical treatment should be considered in refractory patients with partial-onset seizures. Alternative therapies such as ketogenic diet might be considered in some children. ${ }^{24}$

Similarly, patients who do not improve with the first add-on 
drug should be re-evaluated, tried on alternative add-on agents, or considered for surgery.

\section{Controlled on Polytherapy}

Patients whose seizures are controlled on polytherapy should be re-evaluated periodically to determine the need for multiple drug therapy. Although the polytherapy may be responsible for seizure control, it is also possible that the second drug alone might be effective. ${ }^{7}$ Side effects are increased on polytherapy, ${ }^{8}$ however, it is not clear whether this is due to the number of medications or to the total drug load. ${ }^{25}$ Patients may not have obvious side effects, however, there may be subtle cognitive problems that become apparent in retrospect only after one of the drugs is discontinued. The ongoing cost of multiple medications may also be a significant issue. Continued polytherapy may also increase the risk of teratogenicity in women of childbearing age. ${ }^{26-29}$ However, patients may be reluctant to consider a switch to monotherapy with the second agent because of uncertainty regarding seizure recurrence. The critical issue is often the ability to continue driving. If patients are switched to monotherapy under these circumstances, they should be warned not to drive until it is reasonably clear that this strategy is successful. They may have to be reported to the Ministry of Transportation in some jurisdictions.

Withdrawing medications in patients on polytherapy can produce complex drug interactions. For example, discontinuing enzyme-inducing agents such as phenytoin or phenobarbital may increase the plasma levels of drugs such as lamotrigine ${ }^{30}$ or topiramate ${ }^{31}$ This might partially compensate for the antiepileptic effects of the drug being withdrawn, however, it could also cause side effects from the remaining drugs. Conversely, stopping valproate in a patient taking lamotrigine could result in sub-optimal lamotrigine levels. ${ }^{30,32}$ An increase in seizures under these conditions could be managed by increasing the lamotrigine dose rather than re-introducing valproate.

\section{Not Controlled on Polytherapy}

Patients whose seizures are not controlled on multiple medications should have their diagnosis and treatment critically reevaluated. A careful history will usually identify which, if any, of the medications significantly reduced the frequency or severity of the seizures. In some cases it may become clear that none of the drugs were effective. A gradual reduction in the number of medications may simplify management, reduce side effects and cost and improve the patient's quality of life even if the seizures are unaltered.

\section{Change in Medical Condition}

A significant change in the patient's general medical condition or pregnancy should also prompt a re-evaluation of their treatment. For example, the risk of fetal malformations increases with polypharmacy. ${ }^{26-29}$ Side effects may increase during pregnancy, particularly with multiple medications. In addition, drug pharmacokinetics become more complex during pregnancy. ${ }^{33-35}$ For all of these reasons, patients who are contemplating pregnancy should have their medication carefully reviewed and simplified if possible.

Severe hepatic, renal or cardiac disease may alter anti-epileptic drug pharmacokinetics. ${ }^{36-41}$ In addition, these patients are frequently treated with multiple other medications which may interact with the anti-epileptic drugs. ${ }^{42-44}$ This may also result in pharmacodynamic interactions which lead to side effects or seizures. ${ }^{41}$ Drug toxicity may become more difficult to evaluate and manage under these circumstances. Similar considerations may apply in some elderly patients. ${ }^{45}$ Under these circumstances, it is appropriate to try to reduce the number of antiepileptic drugs.

The framework described above is intended to provide a guide for clinical decision making, however, successful management requires individualization of drug therapy for each patient (Table 2).

\section{REFERENCES}

1. Coll Grp Study of Epilepsy. Prognosis of epilepsy in newly referred patients: a multicentre prospective study of the effects of monotherapy on the long- term course of epilepsy. Epilepsia 1992; 33: 45-51.

2. Heller AJ, Chesterman P, Elwes RDC, et al. Phenobarbitone, phenytoin, carbamazepine, or sodium valproate for newly diagnosed adult epilepsy: a randomized comparative monotherapy trial. J Neurol Neurosurg Psychiatry 1995; 58: 44-50.

3. De Silva M, MacArdle B, McGowan M, et al. Randomised comparative monotherapy trial of phenobarbitone, phenytoin, carbamazepine, or sodium valproate for newly diagnosed childhood epilepsy. Lancet 1996; 347: 709-713.

4. Mattson RH, Cramer JA, Collins JF, et al. Comparison of carbamazepine, phenobarbital, phenytoin, and primidone in partial and secondarily generalized tonic-clonic seizures. N Engl J Med 1985; 313: 145-151.

5. Coll Grp Study of Epilepsy. Prognosis of epilepsy in newly referred patients: a multicenter prospective study. Epilepsia 1988; 29: 236-243.

6. Mattson RH, Cramer JA, Collins JF, V.A. Epilepsy Coop. A comparison of valproate with carbamazepine for the treatment of complex partial seizures and secondarily generalized tonicclonic seizures in adults. N Engl J Med 1992; 327: 765-771.

7. Brodie MJ, Yuen AWC. Lamotrigine substitution study: evidence for synergism with sodium valproate? Epilepsy Res 1997; 26: 423-432.

8. Reynolds EH, Shorvon S. Monotherapy or polytherapy in epilepsy. Epilepsia 1981; 22: 1-10.

9. Brodie MJ, Richens A, Yuen AWC. Double-blind comparison of lamotrigine and carbamazepine in newly diagnosed epilepsy. Lancet 1995; 345: 476-479.

10. Reunanen M, Dam M, Yuen AWC. A randomized open multicentre comparative trial of lamotrigine and carbamazepine as monotherapy in patients with newly diagnosed or recurrent epilepsy. Epilepsy Res 1996; 23: 149-155.

11. Kälviäinen R, Äikiä M, Saukkonen AM, Mervaala E, Riekkinen PJ, Sr. Vigabatrin vs. carbamazepine monotherapy in patients with newly diagnosed epilepsy - a randomized, controlled study. Arch Neurol 1995; 52: 989-996.

12. Tanganelli P, Regesta G. Vigabatrin vs. carbamazepine monotherapy in newly diagnosed focal epilepsy: a randomized response conditional cross-over study. Epilepsy Res 1996; 25: 257-262.

13. Chadwick D, Anhut H, Murray G, et al. Int.Gabapentin monotherapy study group. Gabapentin (GBP; Neurontin) monotherapy in patients with newly-diagnosed epilepsy: results of a double-blind fixed dose study comparing three doses of gabapentin and openlabel carbamazepine. Epilepsia 1997; 38: 34.

14. Murray $\mathrm{G}$, Anhut $\mathbf{H}$, Greiner $\mathrm{M}$, et al. Int.Gabapentin monotherapy study group. Gabapentin (Neurontin) monotherapy: results of a multicentre study comparing gabapentin and carbamazepine in patients with newly diagnosed partial seizures. Epilepsia 1997; 38: 205.

15. Sachdeo RC, Reife RA, Lim P, Pledger G. Topiramate monotherapy for partial onset seizures. Epilepsia 1997; 38: 294-300. 
16. Canadian Clobazam Study Group for Childhood Epilepsy. Monothcrapy clobazam vs. carbamazepine vs. phenytoin in childhood epilepsy: a double blind randomized trial with 220 Canadian children. Can J Neurol Sci 1996; 23: S18.

17. Lapovilla G, Gatti A, Veggiotti PA. Lamotrigine monotherapy in the treatment of absence seizures in children. Epilepsia 1997; 38: 95.

18. MRC Antiepil Drug Withdrl Stdy Grp. Prognostic index for recurrence of seizures after remission of epilepsy. Br Med J 1993; 306: 1374-1378.

19. Dooley J, Gordon K, Camfield P, Camfield C, Smith E. Discontinuation of anticonvulsant therapy in children free of seizures for 1 year: a prospective study. Neurology 1996; 46: 969-974.

20. Leppik IE. Compliance during treatment of epilepsy. Epilepsia 1988; 29 (Suppl 2): S79-S84.

21. Stanaway L, Lambie DG, Johnson RH. Noncompliance with anticonvulsant therapy as a cause for seizures. $\mathrm{N} Z$ Med J 1985; 98 : 150-152.

22. Schmidt D, Richter K. Alternative single anticonvulsant drug therapy for refractory epilepsy. Ann Neurol 1986; 19: 85-87.

23. Schmidt D, Gram L. Monotherapy versus polytherapy in epilepsy. CNS Drugs 1995; 3: 194-208.

24. Prasad AN, Stafstrom CF, Holmes GL. Alternative epilepsy therapies: the ketogenic diet, immunoglobulins, and steroids. Epilepsia 1996; 37: S81-S95

25. Deckers CLP, Hekster YA, Keyser A, Meinardi H, Renier WO. Reappraisal of polytherapy in epilepsy: a critical review of drug load and adverse effects. Epilepsia 1997; 38: 570-575.

26. Kaneko S, Otani K, Kondo T, et al. Malformation in infants of mothers with epilepsy receiving antiepileptic drugs. Neurology 1992; 42 (Suppl. 5): 68-74.

27. Dravet C, Julian C, Legras C, et al. Epilepsy, antiepileptic drugs, and malformations in children of women with epilepsy: a French prospective cohort study. Neurology 1992; 42 (Suppl. 5): 75-82.

28. Lindhout D. Pharmacogenetics and drug interactions: role in antiepileptic- drug-induced teratogenesis. Neurology 1992; 42 Suppl. 5: 43-47.

29. Samrén EB, Van Duijn CM, Koch S, et al. Maternal use of antiepileptic drugs and the risk of major congenital malformations: a joint European prospective study of human teratogenesis associated with maternal epilepsy. Epilepsia 1997; 38: $981-990$
30. Eriksson AS, Hoppu K, Nergardh A, Boreus L. Pharmacokinetic interactions between lamotrigine and other antiepileptic drugs in children with intractable epilepsy. Epilepsia 1996; 37: 769-773.

31. Johannessen SI. Pharmacokinetics and interaction profile of topiramate: review and comparison with other newer antiepileptic drugs. Epilepsia 1997; 38: S18-S23.

32. Anderson GD, Yau MK, Gidal BE, et al. Bidirectional interaction of valproate and lamotrigine in healthy subjects. Clin Pharmacol Ther 1996; 60: 145-156.

33. Tomson T, Lindbom U, Ekqvist B, Sundqvist A. Disposition of carbamazepine and phenytoin in pregnancy. Epilepsia 1994; 35: 131-135.

34. Tomson T, Lindbom U, Ekqvist B, Sundqvist A. Epilepsy and pregnancy: a prospective study of seizure control in relation to free and total plasma concentrations of carbamazepine and phenytoin. Epilepsia 1994; 35: 122-130.

35. Yerby MS, Devinsky O. Epilepsy and pregnancy. Adv Neurol 1994; 64: 45-63.

36. Bourgeois BFD. Important pharmacokinetic properties of antiepileptic drugs. Epilepsia 1995; 36: S1-S7.

37. Elwes RDC, Binnie CD. Clinical pharmacokinetics of newer antiepileptic drugs - lamotrigine, vigabatrin, gabapentin and oxcarbazepine. Clin Pharmacokinet 1996; 30; 403-415.

38. Perucca E. Pharmacokinet profile of topiramate in comparison with other new antiepileptic drugs. Epilepsia 1996; 37: S8-S13.

39. Battino D, Estienne $M$, Avanzini $G$. Clinical pharmacokinetics of antiepileptic drugs in paediatric patients. 2. Phenytoin, carbamazepine, sulthiame, lamotrigine, vigabatrin, oxcarbazepine and felbamate. Clin Pharmacokinet 1995; 29: 341-369.

40. Battino D, Estienne M, Avanzini G. Clinical pharmacokinetics of antiepileptic drugs in paediatric patients. 1. Phenobarbital, primidone, valproic acid, ethosuximide and mesuximide. Clin Pharmacokinet 1995; 29: 257-286.

41. Boggs JG. Seizures in medically complex patients. Epilepsia 1997; 38: S55-S59.

42. Graves NM. Neuropharmacology and drug interactions in clinical practice. Epilepsia 1995; 36: S27-S33

43. Cloyd J. Pharmacokinetic pitfalls of present antiepileptic medications. Epilepsia 1991; 32 (Suppl 5): S53-S65.

44. Brodie MJ. Drug interactions in epilepsy. Epilepsia 1992; 33 (Suppl. 1): S13-S22.

45. Willmore LJ. The effect of age on pharmacokinetics of antiepileptic drugs. Epilepsia 1995; 36: S14-S21. 